\title{
Quantifying extreme climatic conditions for maize production using RZWQM in Siping, Northeast China
}

\author{
Haijun Liu' ${ }^{1,2 *}$ Yu Liu ${ }^{3}$, Liwei Zhang ${ }^{1,2}$, Zhijun Zhang ${ }^{1,2}$, Zhuangzhuang Gao ${ }^{1,2}$ \\ (1. Beijing Key Laboratory of Urban Hydrological Cycle and Sponge City Technology, Beijing 100875, China; \\ 2. College of Water Sciences, Beijing Normal University, Beijing 100875, China; \\ 3. School of Civil Engineering and Hydraulic Engineering, Ningxia University, Yinchuan 750021, China)
}

\begin{abstract}
Climate change has a great influence on agricultural production, especially under extreme climatic conditions. In this study, Root Zone Water Quality Model (RZWQM) was used to predict grain yields of maize in the Siping region, Jilin Province, Northeast China during the period from 1951 to 2015; and the response of grain yield to main climatic variables was qualitatively analyzed, especially in three special years of 1954, 2000 and 2009 . Results showed that $1{ }^{\circ} \mathrm{C}$ increase for minimum, maximum and mean air temperatures may produce $1224 \mathrm{~kg} / \mathrm{hm}^{2}, 1860 \mathrm{~kg} / \mathrm{hm}^{2}$ and $1540 \mathrm{~kg} / \mathrm{hm}^{2}$ more grain yields, respectively, and seasonal rainfall amount of less than $450 \mathrm{~mm}$, especially at the flowering and grain filling stages, greatly reduced grain yields. In the years of 1954,2000 and 2009 , grain yields were reduced by $41 \%, 47 \%$ and $40 \%$ compared to their mean value, respectively, correspondingly because of extra low temperature (lower by $2.1{ }^{\circ} \mathrm{C}-2.3^{\circ} \mathrm{C}$ ), less rainfall at the grain filling stage $(36 \mathrm{~mm})$ and extra high temperature (higher by $\left.1.7^{\circ} \mathrm{C}-1.8^{\circ} \mathrm{C}\right)$, and less seasonal rainfall $(252 \mathrm{~mm})$. To reduce extreme climate's effects on grain yield, it is suggested that supplementary irrigation the flowering and grain filling stages should be provided when rainfall is much less at this stage and also appropriate maize species based on the longtime weather forecast should be selected.
\end{abstract}

Keywords: climate change, RZWQM, extra low and high temperatures, seasonal rainfall distribution, maize yield response, Northeast China

DOI: $10.25165 /$ j.ijabe. 20191202.3388

Citation: Liu H J, Liu Y, Zhang L W, Zhang Z J, Gao Z Z. Quantifying extreme climatic conditions for maize production using RZWQM in Siping, Northeast China. Int J Agric \& Biol Eng, 2019; 12(2): 111-122.

\section{Introduction}

Climate change has been confirmed worldwide ${ }^{[1]}$. This change has greatly affected agricultural production in the past century and also will exert more impact on agricultural production in the future ${ }^{[1]}$. It is reported that, the effects of climate change on crop and terrestrial food production are evident in several regions of the world (high confidence); negative impacts of climate trends have been more common than positive ones ${ }^{[2]}$. In China, climate change may create a potential advantage for the development of agriculture, rather than a risk, especially for agriculture in the provinces of the Northeast, Northwest and North regions ${ }^{[3]}$. Chen et al ${ }^{[3]}$ further pointed out that, the total impact of simulated climate change scenarios on net crop revenues per hectare at a Chinese national total level, was an increase of between 79 and 207 USD per hectare for the 2050s, and an increase from 140 to 355 USD per hectare for the 2080 s.

\section{Received date: 2017-03-31 Accepted date: 2019-03-13}

Biographies: Haijun Liu, PhD, Professor, research interests: irrigation methods, agricultural water management and fertigation, Email: shanxilhj@bnu.edu.cn; Yu Liu, Master, research interests: agricultural water management and climate change, Email: liuyu098@163.com; Liwei Zhang, Master, research interests: agricultural water management, Email: zlwaie@126.com; Zhijun Zhang, Master, research interests: agricultural water management and climate change, Email: zhijunzhang0722@163.com; Zhuangzhuang Gao, research interests: agricultural water management and fertigation, Email: bnugaozz@ mail.bnu.edu.cn.

*Corresponding Author: Haijun Liu, PhD, Professor, research interests: irrigation methods, agricultural water management and fertigation. Beijing Key Laboratory of Urban Hydrological Cycle and Sponge City Technology, and College of Water Sciences, Beijing Normal University, Beijing 100875, China. Tel: +86-13681334108, Email: shanxilhj@bnu.edu.cn.
With the climate change, extreme weather, including drought, low or high temperatures, occurred more frequently in the last century, and will intensify in the 21 st century ${ }^{[4-6]}$. And this extreme weather has made great influence on crop production ${ }^{[2,7,6]}$. For example in 7 of the 10 years between 2000 and 2009, drought caused on average more than 4.7 billion USD in agricultural losses annually across portions of the United States, especially in the summer of 2001, drought severely reduced cereal and vegetable production in Guatemala, Honduras, El Salvador, Nicaragua, and portions of other Central American countries ${ }^{[6]}$. Excessive heat generally may cause reduction in grain number (sterility and abortion of grains) during anthesis and reduce duration of the grainfilling period, which lastly reduce grain yields of $\operatorname{crops}^{[8,9]}$. In North China, a long period drought from November in 2008 to March in the 2009 resulted in a great water resource crisis, and the drought-suffered farmland increased $220 \%$ as compared to the normal year in the $2010^{[10]}$.

Maize is one of the main crops in the world ${ }^{[11-13]}$, as well as in China $^{[14,15]}$. In 2014, the production of grain maize in China was 22 million tons, which account for $36 \%$ of total grain production ${ }^{[10]}$ The northeast China, including Jilin, Liaoning and Heilongjiang provinces, is one of the main maize cultivation regions in China. The total cultivation area of maize in the Northeast China accounted for $31 \%$ and maize grain yield accounted for $34 \%$ of the total Chinese national ${ }^{[10]}$. Mostly, rainfall in the Northeast China can match the maize evapotranspiration, therefore, maize is always cultivated under rainfed condition, i.e. no irrigation throughout the maize growing seasons. Due to the radiation limit, maize is generally planted once a year. The growth period of maize in the Northeast China is about $150 \mathrm{~d}$, which is much longer than those (about 90-120 d) in the North China plain and south China 
region $^{[16,3,14]}$. This long growth period generally resulted in a higher grain yield of maize in the Northeast China ${ }^{[17]}$. The maize yield per unit in the northeast China is approximately $10 \%$ higher than the national mean ${ }^{[10]}$.

Recently, It has been reported that climate in the Northeast China has changed greatly. Diurnal minimum, maximum and average air temperature showed increasing trend, while no obvious trend has been found for rainfall during the crop growth period, mainly from May to September ${ }^{[16]}$. Chen et al. ${ }^{[17]}$ found in the Northeast China that, the historic increasing in temperature has led to annually increments of $16.6 \mathrm{~kg} / \mathrm{hm}^{2}, 15.5 \mathrm{~kg} / \mathrm{hm}^{2}$ and $3.2 \mathrm{~kg} / \mathrm{hm}^{2}$ in rice, maize and soybean yields, respectively. It is also reported that, rainy days in the Northeast China had a significant decreasing trend and the rain intensity increased greatly; the nighttime warming rate was much higher than that for daytime, and radiation is predicted to increase significantly during 2041-2070 in the maize growing season ${ }^{[18,19]}$.

Root Zone Water Quality Model (RZWQM) is characterized by detailed soil water and soil nutrient simulations and used for a wide range of management effects on crop production and environmental quality ${ }^{[20,21]}$. Recently this model has been used to estimate climate change effects on crops production. For example in the Colorado of USA, it was estimated using RZWQM that climate change decreased maize yield by $21 \%$ and biomass by $7 \%$ later in the $21^{\text {st }}$ century (2070-2091) under full irrigation, compared to those in the current climate, while the corresponding reductions were $14 \%$ and $3 \%$ under deficit irrigation ${ }^{[22]}$. In the Central Great Plains of USA, maize yield was estimated to decrease by $11.3 \%-27.7 \%$ because of the shortening of growing period caused by increased temperature ${ }^{[23]}$. Wang et al. ${ }^{[24]}$ estimated an increase rate of $28 \%$ for soybean due to $\mathrm{CO}_{2}$ enrichment, but a decrease rate of $-14.7 \%$ for maize because of few days to physiological maturity caused by temperature increase in the future in Iowa. Sun et al. ${ }^{[25]}$ modelled maize yields under rainfed and water non-limiting conditions in the Corn Belt of Northeast China using RZWQM and reported that maize potential yield was positively related to precipitation in July in both Aeolian sandy soil and black soil. Therefore, Wang et al. ${ }^{[24]}$ stressed using agricultural system models like RZWQM is an acceptable way to assess climate change impacts on water quality and crop production.

Climate changes may greatly influence maize growth and yield, especially in some extreme climate years. Therefore, the objectives of this study were to (1) calibrate and validate RZWQM in the Siping of Northeast China, (2) predict maize yield and investigate their variation in the last 65 years (1951-2015), (3) compare the relationships between grain yield of maize and main climatic factors and find their relationship, and (4) analyze the main reasons for grain yield reduction in three extreme climate seasons and propose some solutions to release these climatic effects.

\section{Materials and methods}

\subsection{Study region}

The study region, Siping area, is a typical maize cultivation region in the Northeast China (Figure 1). In 2014, maize cultivation area accounted for $93.7 \%$ of the total farmland in Siping region. Climate in this region is the typical sub-humid temperature continental climate. Annual mean temperature is $6.5^{\circ} \mathrm{C}$, wind speed is $3.0 \mathrm{~m} / \mathrm{s}$, and annual total sunshine hours are $2700 \mathrm{~h}$. Mean annual rainfall is $631 \mathrm{~mm}$, more than $70 \%$ occurs from July to September. Recently, it is observed that there was a great climate change in this region, including temperature increasing and radiation reduction ${ }^{[18,19]}$. This change may greatly affect maize production.

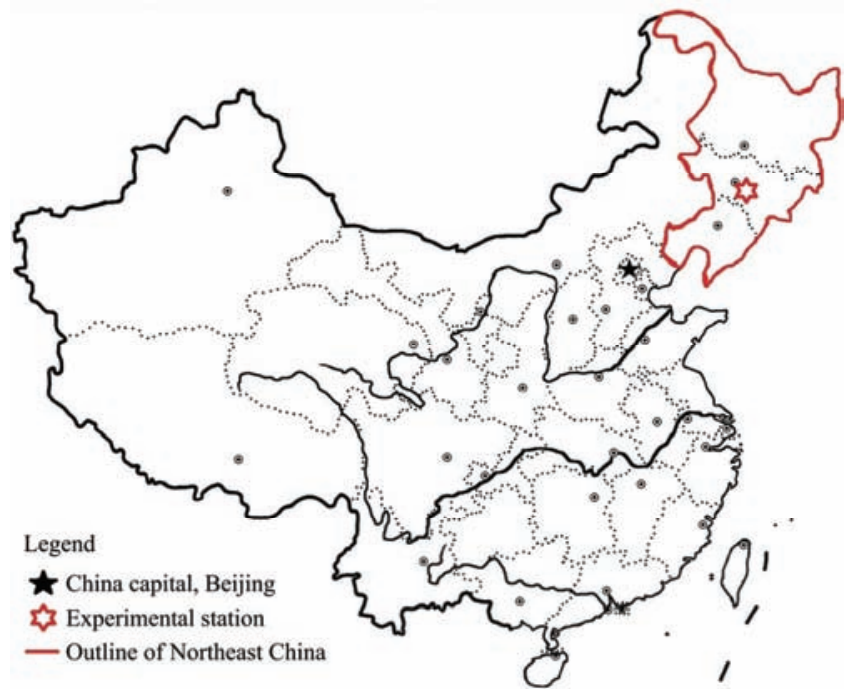

Figure 1 Schematic description of the Northwest China region and experimental station site

Soil texture in the study region is uniform over the root zone. In the $0-100 \mathrm{~cm}$ depth, the soil texture is silty clay loam, with $14.8 \%$ in sand, $49.1 \%$ in silt and $36.1 \%$ in clay. In the 100 $120 \mathrm{~cm}$ depth, the soil texture is clay loam, with $21.2 \%$ in sand, $48.1 \%$ in silt and $30.7 \%$ in clay. The bulk densities in $0-20 \mathrm{~cm}$ depth were measured $1.31 \mathrm{~g} / \mathrm{cm}^{3}, 1.53 \mathrm{~g} / \mathrm{cm}^{3}$ in the $20-100 \mathrm{~cm}$ depth, and $1.60 \mathrm{~g} / \mathrm{cm}^{3}$ in the $100-120 \mathrm{~cm}$ depth. The average saturated hydraulic conductivity (Ks), field capacity (FC), and permanent wilting point (PWP) over the $0-120 \mathrm{~cm}$ depth were measured as $0.21-0.49 \mathrm{~cm} / \mathrm{h}, 0.40-0.46 \mathrm{~cm}^{3} / \mathrm{cm}^{3}$, and $0.0 .07-$ $0.09 \mathrm{~cm}^{3} / \mathrm{cm}^{3}$, respectively. The detailed information of the soil texture is listed in the Table 1.

Table 1 Soil physical and hydraulic parameters in the study region

\begin{tabular}{|c|c|c|c|c|c|c|c|c|}
\hline \multirow{2}{*}{ Soil layer } & \multicolumn{3}{|c|}{ Particle percentage/\% } & \multirow{2}{*}{$\begin{array}{l}\text { Bulk density/ } \\
\qquad \mathrm{g} \cdot \mathrm{cm}^{-3}\end{array}$} & \multirow{2}{*}{ Soil texture } & \multicolumn{2}{|c|}{ Soil water $/ \mathrm{cm}^{3} \cdot \mathrm{cm}^{-3}$} & \multirow{2}{*}{$\begin{array}{c}\mathrm{Ks} / \\
\mathrm{cm} \cdot \mathrm{h}^{-1}\end{array}$} \\
\hline & Sand & Silt & Clay & & & Saturated & Wilting point & \\
\hline $0-20$ & 16.7 & 45.8 & 37.5 & 1.31 & & 0.428 & 0.092 & 0.325 \\
\hline $20-40$ & 15.3 & 44.9 & 39.8 & 1.51 & & 0.460 & 0.088 & 0.486 \\
\hline $40-60$ & 12.1 & 50.8 & 37.1 & 1.49 & Silty clay loam & 0.459 & 0.088 & 0.493 \\
\hline $60-80$ & 13.0 & 53.9 & 33.1 & 1.52 & & 0.450 & 0.083 & 0.463 \\
\hline $100-120$ & 21.2 & 48.1 & 30.7 & 1.60 & Clay loam & 0.405 & 0.075 & 0.213 \\
\hline
\end{tabular}

\subsection{Field experiment}

A two-year field experiment (2014 and 2015 maize growth seasons) was conducted at the Lishu Experimental Station of China
Agricultural University, Siping City of Jilin Province (latitude $43^{\circ} 16^{\prime} 42^{\prime \prime} \mathrm{N}$, longitude $124^{\circ} 26^{\prime} 10^{\prime \prime} \mathrm{E}$, altitude $184 \mathrm{~m}$ ), to calibrate and validate the Root Zone Water Quality Model (RZWQM). 
The maize (Zea mays L.) variety in the two seasons was Liangyu 11 , a variety widely used in the study region. Maize was sowed on May 1 and harvested on September 25 and 26 in the 2014 and 2015 seasons, respectively. Maize was planted in narrow-wide row, with spaces between rows of 40 and $80 \mathrm{~cm}$, respectively. The spaces between plants in the row were $25 \mathrm{~cm}$. This plant layout yielded a plant population of 66700 plants $/ \mathrm{hm}^{2}$.

There were two experimental treatments in each year, rainfed (RF) and irrigated (IR). The experimental field for each treatment was measured $30 \mathrm{~m}$ in length and $24 \mathrm{~m}$. The maize plants in the IR treatment were irrigated using basin irrigation method. The IR plot was divided into 8 subplots, with $15 \mathrm{~m}$ in length and $6 \mathrm{~m}$ in width for each subplot. Ridged were prepared between subplots for irrigation in IR treatment. There were no subplots and ridges in the RF field. Because rainfall was plentiful in the maize season in 2014, therefore, there was no irrigation; also there was no IR treatment. In the year of 2015, rain was very low from the late July to the beginning of August, therefore maize plants in the IR treatments were irrigated using $60 \mathrm{~mm}$ water on July 24 . After that, rainfall was enough and then no irrigation was applied in the IR treatment.

Agronomic management practices in this field study were the same as those in the experimental station and the local region. A N-P-K compound fertilizer was used as base fertilizer and applied into soil with plough before maize sowing. The amounts for N, $\mathrm{P}_{2} \mathrm{O}_{5}$ and $\mathrm{K}_{2} \mathrm{O}$ were $192 \mathrm{~kg} / \mathrm{hm}^{2}, 104 \mathrm{~kg} / \mathrm{hm}^{2}, 120 \mathrm{~kg} / \mathrm{hm}^{2}$, respectively, in both seasons. There was no other fertilizers were applied during the maize growth season.

\subsection{Model description}

\subsubsection{RZWQM}

The Root Zone Water Quality Model (RZWQM) is an integrated agricultural system model that includes biological, physical and chemical processes and simulates the impact of soil-water-crop management practices on agricultural production and soil-water quality ${ }^{[26]}$. In the RZWQM model, the Green-Ampt Equation is used for water infiltration and the Richards' Equation for water redistribution in soil layers. Daily potential evapotranspiration is estimated using the Shuttleworth-Wallace Equation. Optional management practices in the model include: tillage, fertilizer application, planting and harvesting operations, irrigation, and surface crop residue dynamics ${ }^{[27-29]}$.

\subsubsection{Model calibration and validation}

The field data of 2014 was firstly used for model calibration. Then the calibrated model was used for validation purposes without changing the calibrated parameters by using the data measured in the 2015 season. The manual calibration procedure included matching simulation results with measured soil water, leaf area index (LAI), dry biomass above ground surface at each measurement and grain yields at harvest. Parameters in the Table 1 were used in the RZWQM model to calculate soil water balance. And Table 2 listed the final plant parameters used in the model after model calibration and validation processes.

The performance of the model in predicting the soil water content, leaf area index (LAI), dry biomass above ground surface and grain yield of maize were evaluated using the root mean square error (RMSE), mean relative error (MRE), and coefficient of determination $\left(r^{2}\right)$ as:

$$
R_{M S E}=\sqrt{\frac{1}{n} \sum_{i=1}^{n}\left(P_{i}-Q_{i}\right)^{2}}
$$

$$
\begin{gathered}
M_{R E}=\frac{1}{n} \sum_{i=1}^{n} \frac{\left(P_{i}-Q_{i}\right)}{Q_{i}} \times 100 \% \\
r^{2}=\left\{\frac{\sum_{i=1}^{n}\left(Q_{i}-Q_{a v e}\right)\left(P_{i}-P_{a v e}\right)}{\left[\sum_{i=1}^{n}\left(Q_{i}-Q_{a v w}\right)^{2}\right]^{0.5}\left[\sum_{i=1}^{n}\left(P_{i}-P_{a v e}\right)^{2}\right]^{0.5}}\right\}^{2}
\end{gathered}
$$

where, $n$ is the number of measured and modeled data; $i$ is the $i^{\text {th }}$ data in the total measured number of n; $P$ is the predicted value; and $Q$ is the measured value; $Q_{a v g}$ is the mean value of measured data.

Table 2 Final crop parameters in the DSSAT model of the RZWQM

\begin{tabular}{ccccccc}
\hline Parameters & $\begin{array}{c}\mathrm{P} 1 / \\
{ }^{\circ} \mathrm{C} \cdot \mathrm{d}^{-1}\end{array}$ & $\mathrm{P} 2$ & $\begin{array}{c}\mathrm{P} 5 / \\
{ }^{\circ} \mathrm{C} \cdot \mathrm{d}^{-1}\end{array}$ & $\begin{array}{c}\mathrm{G} 2 / \\
\text { Grains per ear }\end{array}$ & $\begin{array}{c}\mathrm{G} 3 / \\
\mathrm{mg} \cdot(\mathrm{grain} \cdot \mathrm{d})^{-1}\end{array}$ & $\begin{array}{c}\mathrm{PHINT} / \\
{ }^{\circ} \mathrm{C} \cdot \mathrm{d}^{-1}\end{array}$ \\
\hline Values & 380 & 0.34 & 720 & 590 & 11.0 & 48.2
\end{tabular}

The closer the RMSE is to zero, the better the model simulation performance. MRE is better controlled within $\pm 10 \%$. $r^{2}$ is the measure of relationship between two datasets and describes the proportion of the total variance in the measured data that can be explained by the model. $r^{2}$ ranges between 0 and 1 with higher values indicating better simulations. It should be noted that these statistic results are sensitive to a few large errors especially in small data sets ${ }^{[33]}$.

\subsection{Data preparation}

\subsubsection{Experimental data}

Soil water in $0-200 \mathrm{~cm}$ depth was measured with gravity method at $20 \mathrm{~cm}$ intervals every 7-10 d during the experimental period. Three sites were chose for each measure at each treatment.

Crop growth characteristics, including plant leaf area, height and biomass were measured every $10-15 \mathrm{~d}$. At the beginning of the elongation stage, 10 plants were selected at each treatment for seasonal measurements of leaf area and plant height. Leaf area for each plant was the sum of all leaves' area. Each leaf area (LA) was determined with the leaf length $(L)$ and width $(W)$ by the in situ regressed relationship $\mathrm{LA}=0.74 L \cdot W^{[34]}$. Leaf area index (LAI) was computed using the mean total leaf area of each plant divided by the field area occupied by a plant. Plant height measurement stopped when plant grows to its' maximum height in the grain filling and late stages. Five plants at each treatment were cut each measure to determine plant dry biomass.

At harvest, 75 plants were selected at each treatment to investigate grain yields of maize. The grains were naturally dried under the sunshine for approximately $10 \mathrm{~d}$, until the water content of grains were reaching relative constant. The mean value of these 75 plants was the grain yield for the corresponding treatment.

\subsubsection{Meteorological data}

Daily meteorological factors from 1951 to 2015, including rainfall depth, evaporation, maximum and minimum air temperatures, relative humidity, wind speed and solar radiation were obtained from Siping National Meteorological Station (Station No. 54157). Table 3 summarized the meteorological information over the period from 1951 to 2015 in the research region.

To investigate the climatic change's effects on grain yields, grain yields for each year were predicted by the RZWQM using the parameters in the Tables 1 and 2, and the daily climatic data from 1951 to 2015 . Considering the rich precipitation in winter, soil water before the maize sowing always is plentiful and varies slightly over year. Therefore, the initial soil water content from 
0 to $200 \mathrm{~cm}$ depth in the model were those measured before maize sowing in the 2014 and 2015 seasons. The begin day and end day for model running was from May 1 to September 26, indicting the beginning and end of maize season in the study region.

Table 3 Summary on the yearly meteorological factors in the Siping region

\begin{tabular}{|c|c|c|c|c|c|c|c|c|}
\hline & $T_{m e a n}$ & $T_{\max } /{ }^{\circ} \mathrm{C}$ & $T_{\min }$ & $R H / \%$ & Precipitation $/ \mathrm{mm}$ & Solar radiation $/ \mathrm{MJ} \cdot \mathrm{m}^{-2} \cdot \mathrm{a}^{-1}$ & Wind speed $/ \mathrm{m} \cdot \mathrm{s}^{-1}$ & $\operatorname{ETo}^{*} / \mathrm{mm} \cdot \mathrm{a}^{-1}$ \\
\hline Mean & 6.5 & 12.4 & 1.3 & 65 & 631 & 5457 & 3.0 & 897 \\
\hline Max & 8.4 & 13.9 & 3.8 & 74 & 1009 & 5985 & 4.7 & 1045 \\
\hline Min & 4.2 & 10.2 & -0.8 & 58 & 369 & 4771 & 1.9 & 742 \\
\hline
\end{tabular}

Note: *ETo is reference crop evapotranspiration, and calculated with the Penman-Monteith method ${ }^{[35]}$.

To investigate the effect of each climatic variable's changes to yields' variations, firstly the mean values of each day were calculated for each climatic variable over periods from 1951 to 2015 except for rainfall; the rainfall's distribution in the average year was chose those in the 1988; then the maize grain yields under average condition were predicted using the average climatic variables and rainfall in 1988. In three special years with great reductions of grain yields (seeing section 3.4), the grain yields were modeled by replacing one climatic variable with the average value and keeping other climatic variables in the special year. The difference between yields predicted under the initial climate condition and one variable replacement were due to this replaced variables. The big difference in yields indicated greater effect of this climatic variable to yields variation.

\section{Results and discussion}

\subsection{Model calibration and validation}

Figure 2 shows the measured and predicted soil water contents in $0-120 \mathrm{~cm}$ soil layer in the 2014 season, and Figures 3 and 4 show soil water in rainfed and irrigation fields in the 2015 season, respectively. Soil water data set in the 2014 season was used for model calibration and those in 2015 seasons was used for model validation. The statistical results on model calibration and validation are listed in Table 4. In the model calibration process, MRE between the measured and predicted soil water contents in the $0-120 \mathrm{~cm}$ soil layers were less than $10 \%$, and the $r^{2}$ ranged from 0.61 to 0.79 . Also in the model validation process for soil water content in both rainfed and irrigation maize fields in the 2015 season, MREs were generally less than $8 \%$ and $r^{2}$ ranged from 0.53 to 0.86 . These results showed that, the soil hydraulic parameters in Table 1 can be accepted to predict soil water changes in the maize field in the study region under both rainfed and irrigation conditions.

Figure 5 shows the measured and predicted leaf area index (LAI) and dry biomass above ground surface in the model calibration process in the 2014 season, and Figures 6 and 7 show the measured and predicted LAI and dry biomass in the model validation process in the rainfed and irrigation fields in the 2015 season. Table 5 summarizes the statistical results for model calibration and validation processes. And Table 6 shows the measured and predicted grain yields and dry biomass above ground surface under rainfed and irrigation conditions. In the model calibration process, the mean relative error between model and predicted LAIs was $-0.2 \%$ and $r^{2}$ was 0.98 . For the predicted biomass, the MRE was $-7.3 \%$, and $r^{2}$ was 0.98 . Also in the model validation process in the rainfed and irrigation fields of the 2015 season, the MREs for predicating LAIs and biomass were less than $10 \%$, and $r^{2}$ ranged from 0.94 to 0.98 . The relative errors between measured and predicted grain yields was $-1.53 \%$ in the model calibration process in the 2014 season, and was $1.29 \%$ in the model calibration process in the 2015 season under rainfed condition. This model also performed well with a relative error of $-5.03 \%$ for grain yield prediction under irrigation condition in the 2015 season. Therefore, all information in the Figures 5-7 and Tables 5-6 show that the final crop parameters in the DSSAT model of the RZWQM in Table 2 can be accepted for predicting plant LAI, biomass and grain yields in both rainfed and irrigation fields in the study region.
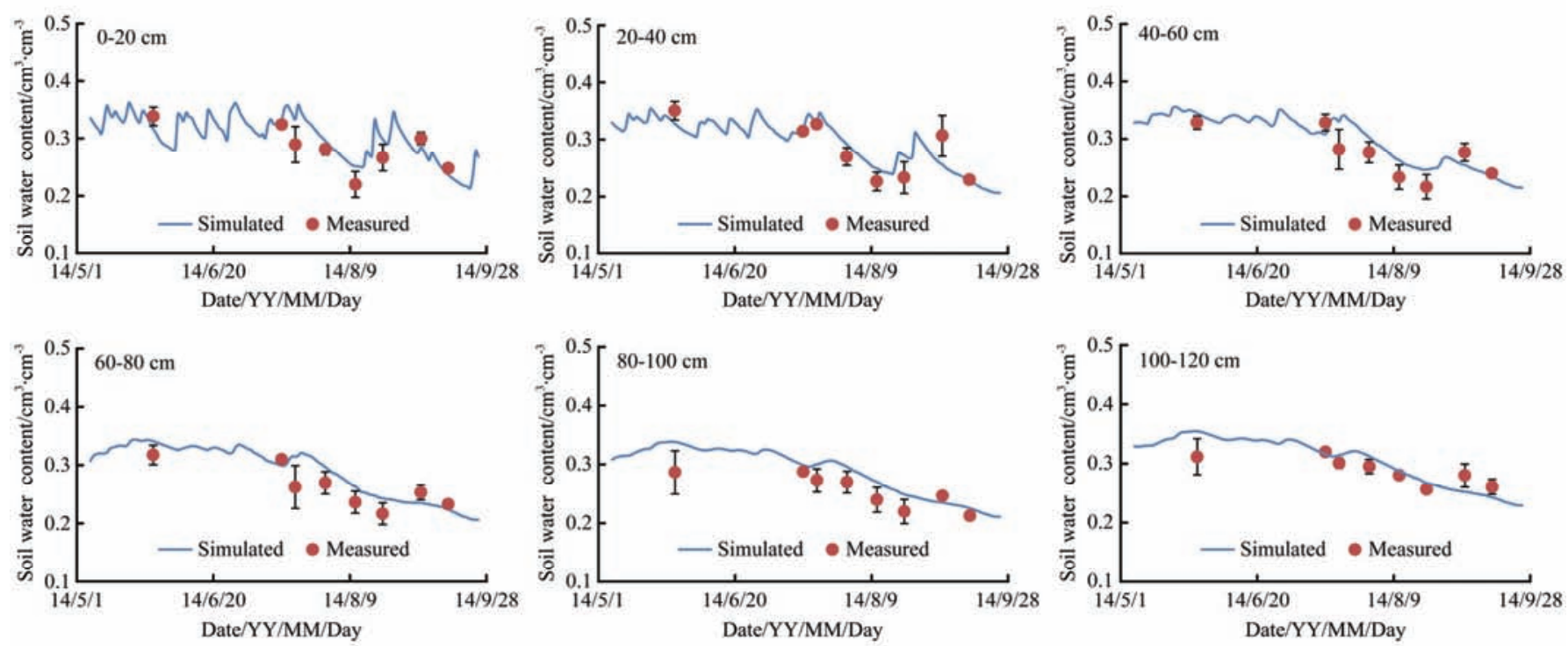

Figure 2 Measured and predicted soil water contents in 2014 season (model calibration process) 

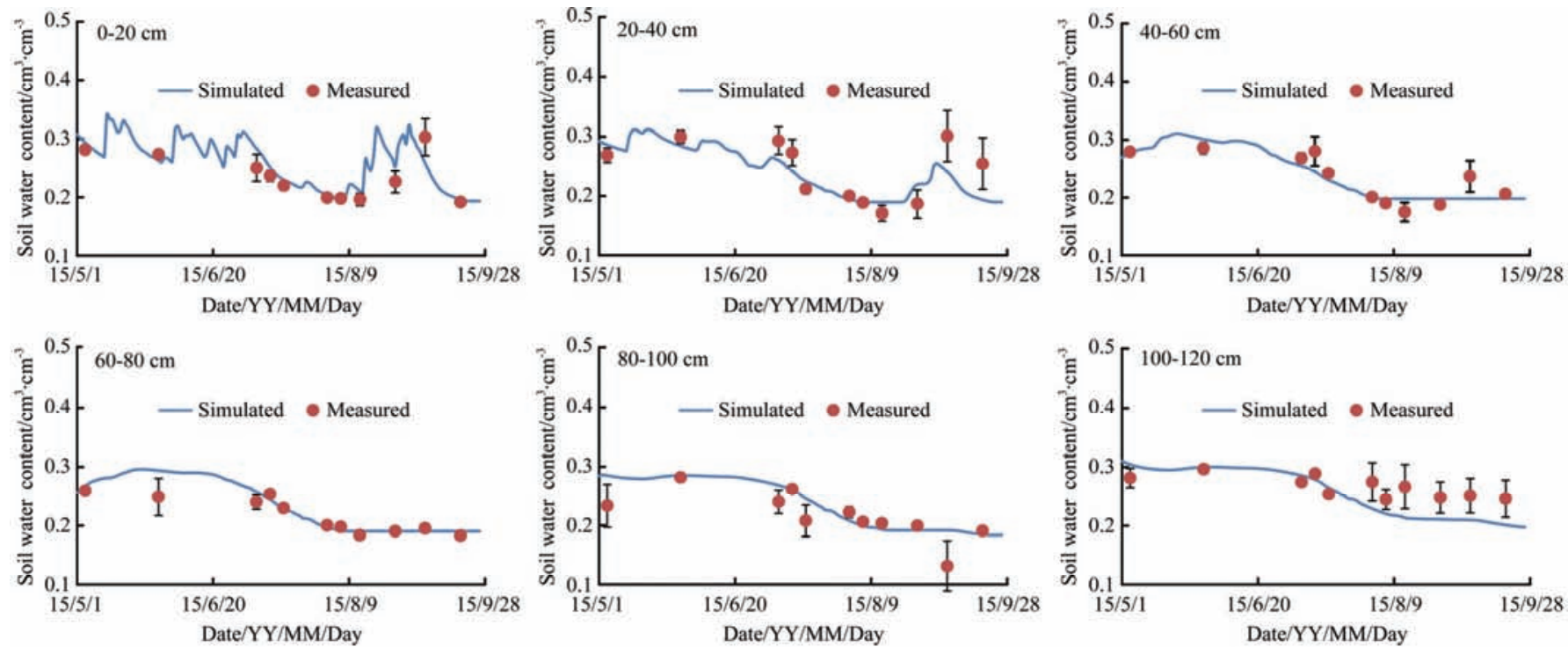

Figure 3 Measured and predicted soil water contents in the rainfed field in 2015 season (in the model validation process)
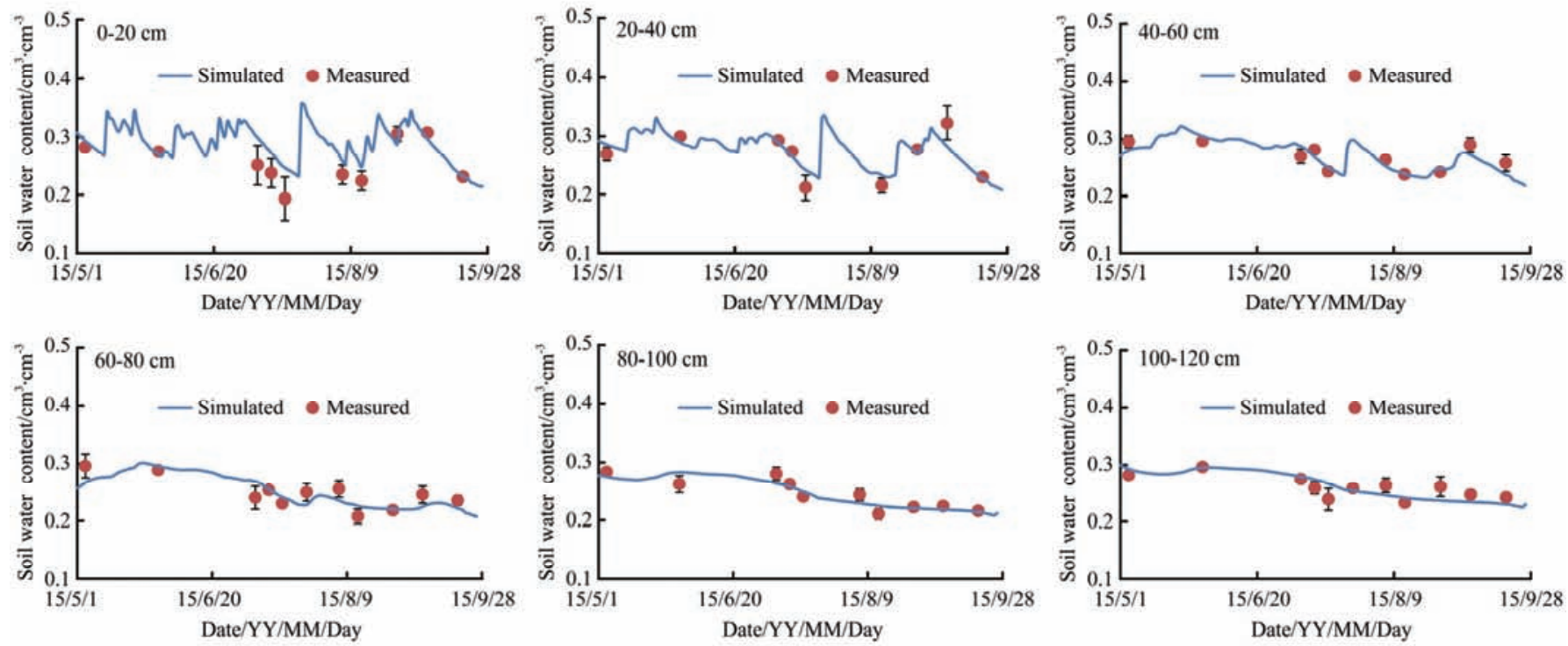

Figure 4 Measured and predicted soil water contents in irrigation fields in 2015 season (in the model validation process)

Table 4 Statistical results of the calibration and validation process of RZWQM for predicting soil water contents in the upper $120 \mathrm{~cm}$ soil layer

\begin{tabular}{|c|c|c|c|c|c|c|c|c|}
\hline \multirow{2}{*}{ Season } & \multirow{2}{*}{ Treatments } & \multirow{2}{*}{ Statistical Parameters } & \multicolumn{6}{|c|}{ Soil layers/cm } \\
\hline & & & 20 & 40 & 60 & 80 & 100 & 120 \\
\hline \multirow{2}{*}{$\begin{array}{c}2014 \\
\text { (model calibration) }\end{array}$} & \multirow{2}{*}{ Rainfed } & $\mathrm{RMSE} / \mathrm{cm}^{3} \cdot \mathrm{cm}^{-3}$ & 0.025 & 0.026 & 0.027 & 0.027 & 0.028 & 0.021 \\
\hline & & $r^{2}$ & 0.61 & 0.67 & 0.65 & 0.66 & 0.79 & 0.72 \\
\hline \multirow{6}{*}{$\begin{array}{c}2015 \\
\text { (model validation) }\end{array}$} & \multirow{3}{*}{ Rainfed } & $\mathrm{RMSE} / \mathrm{cm}^{3} \cdot \mathrm{cm}^{-3}$ & 0.020 & 0.032 & 0.020 & 0.016 & 0.029 & 0.032 \\
\hline & & $\mathrm{MRE} / \%$ & 3.1 & -3.0 & -1.5 & 2.1 & 6.9 & -7.5 \\
\hline & & $r^{2}$ & 0.72 & 0.59 & 0.78 & 0.86 & 0.60 & 0.64 \\
\hline & \multirow{3}{*}{ Irrigation } & $\mathrm{RMSE} / \mathrm{cm}^{3} \cdot \mathrm{cm}^{-3}$ & 0.028 & 0.019 & 0.013 & 0.018 & 0.012 & 0.015 \\
\hline & & $\mathrm{MRE} / \%$ & 7.4 & 0.4 & -1.3 & -1.1 & -0.3 & -0.2 \\
\hline & & $r^{2}$ & 0.58 & 0.78 & 0.68 & 0.53 & 0.79 & 0.56 \\
\hline
\end{tabular}

Table 5 Summary of the performance of the RZWQM for predicting LAI and dry biomass above ground surface in the calibration and validation processes

\begin{tabular}{|c|c|c|c|c|c|c|c|c|c|}
\hline \multirow{3}{*}{ Treatments } & \multicolumn{3}{|c|}{2014 season (Calibration) } & \multicolumn{6}{|c|}{2015 season (validation) } \\
\hline & \multicolumn{3}{|c|}{ Rainfed } & \multicolumn{3}{|c|}{ Rainfed } & \multicolumn{3}{|c|}{ Irrigation } \\
\hline & RMSE & MRE & $r^{2}$ & RMSE & MRE & $r^{2}$ & RMSE & MRE & $r^{2}$ \\
\hline LAI & 0.28 & -0.2 & 0.98 & 0.24 & -0.6 & 0.97 & 0.43 & -8.4 & 0.94 \\
\hline Biomass $/ \mathrm{kg} \cdot \mathrm{hm}^{2}$ & 1088 & -7.3 & 0.98 & 1235 & -9.1 & 0.98 & 1442 & -7.9 & 0.98 \\
\hline
\end{tabular}


Table 6 Measured and predicted grain yields and dry biomass above ground surface at harvest at rainfed and irrigation treatments in 2014 (model calibration) and 2015 (model validation) seasons

\begin{tabular}{|c|c|c|c|c|c|}
\hline Seasons & Treatments & Items & Predicted $/ \mathrm{kg} \cdot \mathrm{hm}^{-2}$ & Observed $/ \mathrm{kg} \cdot \mathrm{hm}^{-2}$ & Relative error $/ \%$ \\
\hline \multirow{2}{*}{ 2014(Calibration) } & \multirow{2}{*}{ Rainfed } & Grain yields & 13017 & 13219 & -1.53 \\
\hline & & Dry biomass & 26180 & 25111 & 4.26 \\
\hline \multirow{3}{*}{ 2015(validation) } & \multirow{2}{*}{ Rainfed } & Grain yields & 10017 & 9890 & 1.29 \\
\hline & & Dry biomass & 20776 & 20621 & 0.75 \\
\hline & Irrigation & Grain yields & 12876 & 13558 & -5.03 \\
\hline
\end{tabular}
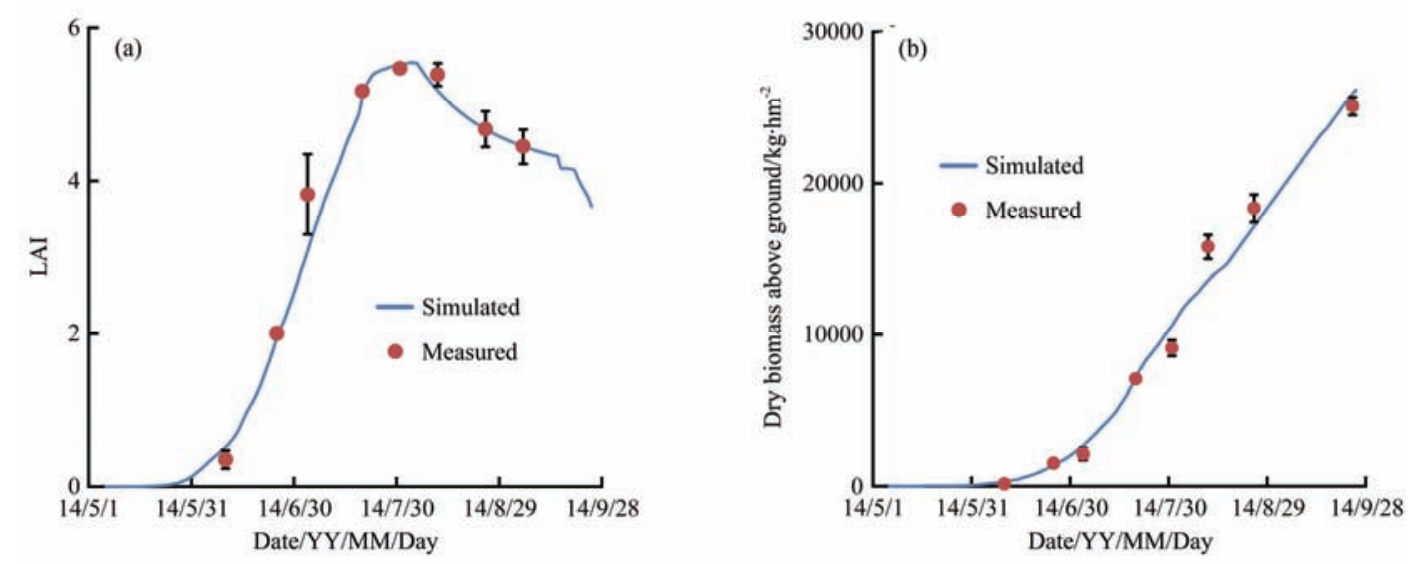

Figure 5 Measured and predicted LAI and dry biomass above ground in the 2014 season (model calibration process)
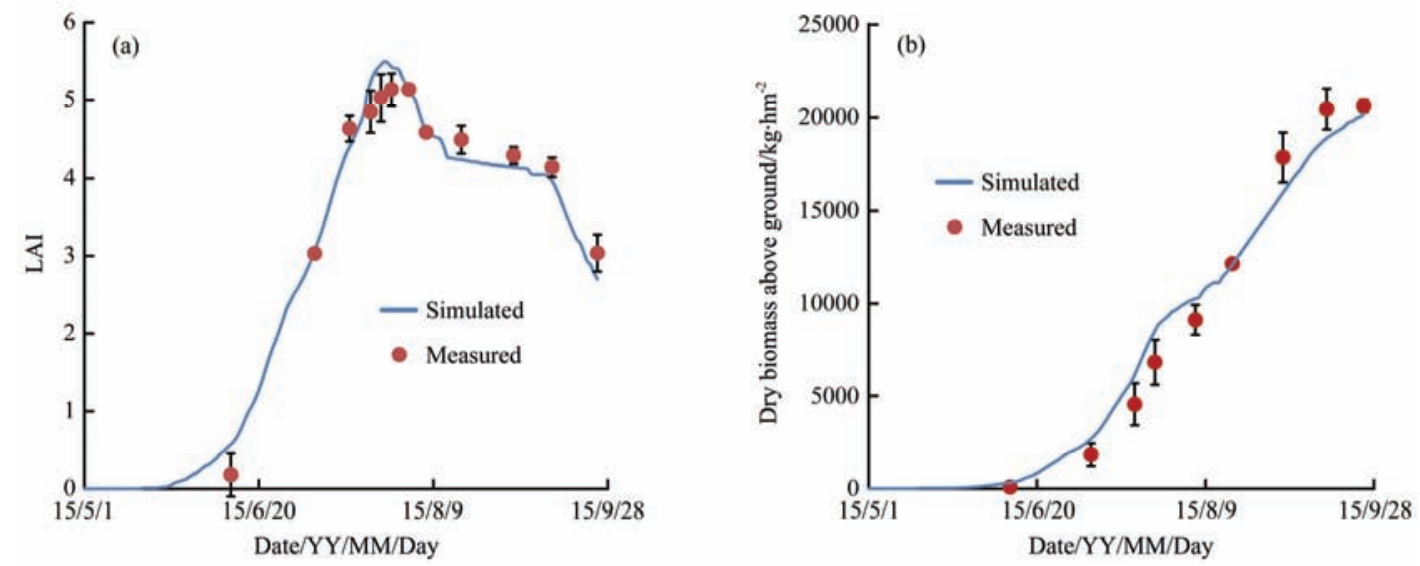

Figure 6 Measured and predicted LAI and dry biomass above ground in the rainfed field in the 2015 season (model calibration process)
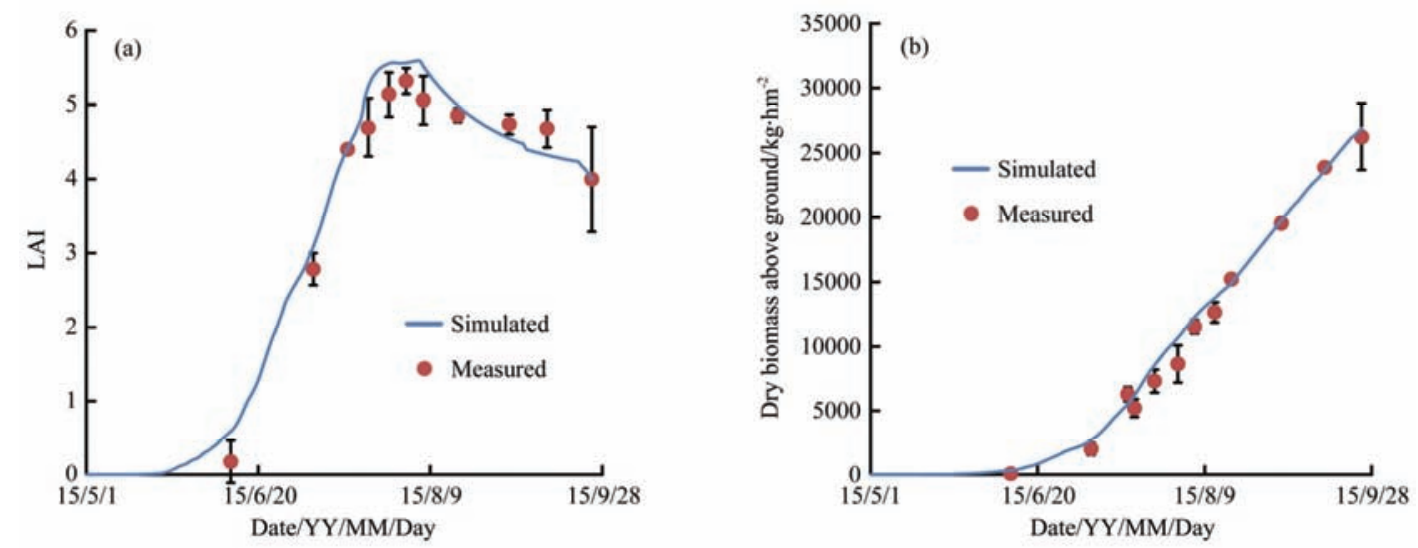

Figure 7 Measured and predicted LAI and dry biomass above ground in the irrigation field in the 2015 season (in model calibration process)

\subsection{Yields variation from 1951 to 2015}

The grain yields of maize were predicted for each year from 1951 to 2015 by RZWQM using the parameters in Tables 1 and 2, and climatic data from the national Weather Station in Siping. Figure 8 shows the modeled grain yields and dry biomass above ground surface at harvest from 1951 to 2015 in the study region. The grain yields mostly positively related to the dry biomass dynamics. It means higher biomass generally yields more grain yields. From 1951 to 2015, grain yields ranged from $6438 \mathrm{~kg} / \mathrm{hm}^{2}$ to $15442 \mathrm{~kg} / \mathrm{hm}^{2}$ with a mean value of $12086 \mathrm{~kg} / \mathrm{hm}^{2}$. These 
yields value is close to the data of $7-13 \mathrm{t} / \mathrm{hm}^{2}$ in the published literatures ${ }^{[36,37]}$, indicating the modeled grain yield is reasonable and acceptable. It should be noted in the Figure 8 that, in the 1954, 2000 and 2009, grain yields were $7177 \mathrm{~kg} / \mathrm{hm}^{2}, 6438 \mathrm{~kg} / \mathrm{hm}^{2}$ and $7296 \mathrm{~kg} / \mathrm{hm}^{2}$, which were respectively lower by $41 \%, 47 \%$ and $40 \%$ than the mean grain value of $12086 \mathrm{~kg} / \mathrm{hm}^{2}$. These great reductions in yields were mainly due to the variation of some climatic factors. The detailed description for yield reduction can be found in the section of 3.4 .

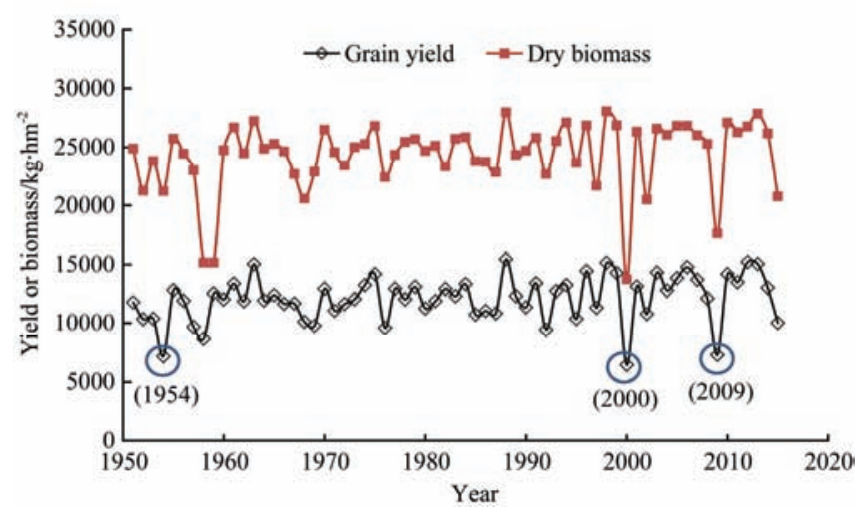

Figure 8 Predicted grain yields and dry biomass above ground surface of maize from 1951 to 2015 in Siping region

\subsection{Yields and climatic factors}

The relationships between grain yields and climatic factors, including minimum, maximum and mean air temperatures, mean daily sunshine hours, relative humidity and seasonal total precipitation were analyzed and the statistical results of correlation coefficients between grain yields and climatic factors are listed in the Table 7. It shows that, grain yields generally increased with the minimum, maximum and mean air temperatures, while sunshine hours, relative humidity and seasonal precipitation did little effects on grain yields' variation. These results were close to some literatures, where maize yields was found to be positively related to temperature increase, and negatively related to radiation decrease, and not significantly related to seasonal rainfall amount $^{[16,17,38]}$.

Table 7 Correlation coefficients between meteorological factors and yield

\begin{tabular}{cccccc}
\hline $\mathrm{T}_{\min }$ & $\mathrm{T}_{\max }$ & $\mathrm{T}_{\text {mean }}$ & Sunshine hours & $\mathrm{RH}$ & Precipitation \\
\hline $0.622^{* *}$ & $0.391^{*}$ & $0.577^{* *}$ & -0.071 & -0.015 & 0.127 \\
\hline Note: $^{* *}$ and & ${ }^{*}$ indicated significant levels of 0.01 and 0.05 , respectively.
\end{tabular}

In the Northeast China, temperature is always considered as important constraint factor for crop cultivation because of the energy limit ${ }^{[39]}$. Rainfall is always another important limit factor for maize production ${ }^{[40]}$. To reduce the rainfall's influences on yields, we only chose yields when rainfall is sufficient. the cases with rainfall higher than $450 \mathrm{~mm}$ was chosen because the seasonal crop evapotranspiration for maize is about $380-520 \mathrm{~mm}$ depending on climatic condition in this region ${ }^{[19]}$. The relationships between the predicted maize yields and minimum, maximum and mean air temperatures are showed in Figure 9. It is clearly shown in Figure 9 that grain yields are linearly increased with the minimum, maximum and mean air temperatures, similar to the result of Chen et al. ${ }^{[17]}$ The regressed lines for yields and each temperature indicates that, $1{ }^{\circ} \mathrm{C}$ increase for minimum, maximum and mean air temperatures may produce more $1224 \mathrm{~kg} / \mathrm{hm}^{2}, 1860 \mathrm{~kg} / \mathrm{hm}^{2}$ and $1540 \mathrm{~kg} / \mathrm{hm}^{2}$ grain yields. These data also indicates that increasing in maximum air temperature may produce $50 \%$ more grain yields as compared to the minimum temperature. Similarly, Chen et al. ${ }^{[16]}$ found that $1.0^{\circ} \mathrm{C}$ increase in the daily minimum temperature in May or September will lead to increments of $303 \mathrm{~kg} / \mathrm{hm}^{2}$ or $284 \mathrm{~kg} / \mathrm{hm}^{2}$ in maize yields, respectively, and temperature increasing trend may enhance maize yield by $7.1 \%-9.8 \%$ when early-maturing hybirds were replaced by middleor late-hybirds in the Jilin Province ${ }^{[39]}$. Zhao et al. ${ }^{[41]}$ further reported mean and maximum air temperatures from May to September, especially in June, July and August, are positively related to maize yield in Jilin Province by using moving average, harmonic average and logistic regression methods. Maize yield also has been reported being increased by $9 \%-16 \%$ under partial and fully mulching condition, mainly because plastic mulching can increase soil temperature during the crop seeding and early growth stages, then accelerate phonological development and advance the timing of anthesis, lastly promote growth and increase yields ${ }^{[42,43]}$. Considering the increasing trend of air temperature in this region ${ }^{[16]}$, maize has a great potential to produce more grain yields in the future under water sufficient condition ${ }^{[39]}$. This study further found that, with daily maximum temperature from $25.5^{\circ} \mathrm{C}$ to $26.5^{\circ} \mathrm{C}$, minimum temperature from $15.0^{\circ} \mathrm{C}$ to $16.0^{\circ} \mathrm{C}$ and mean temperature from $20.0^{\circ} \mathrm{C}$ to $21.0^{\circ} \mathrm{C}$, maize yield may reach at least $14000 \mathrm{~kg} / \mathrm{hm}^{2}$, a higher maize yield in the study region.

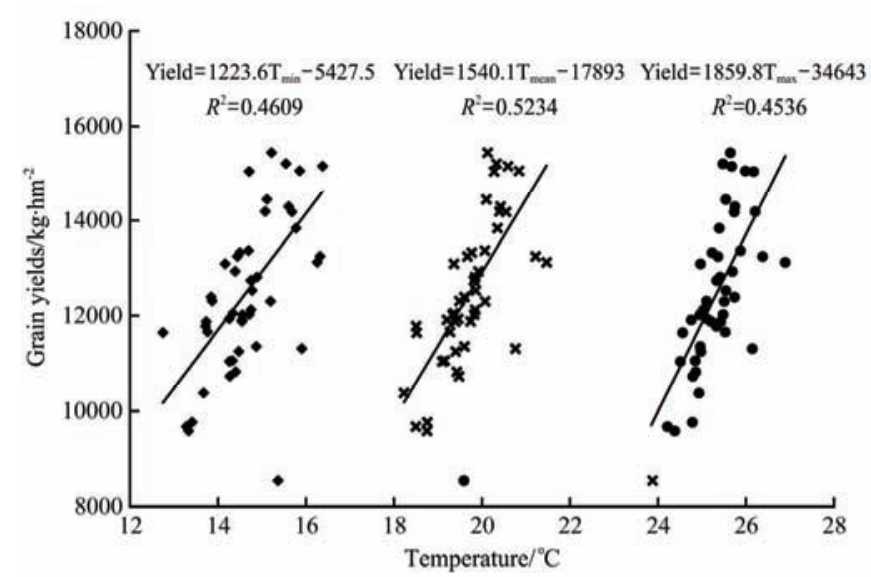

Figure 9 Relationships between predicted grain yields of maize and seasonal mean values of daily maximum, minimum and average temperatures in Siping region

The study region is characterized by rainfed agriculture. Rainfall is the only water resource for crop evapotranspiration. Therefore, rainfall amount and its seasonal distribution are critical to crop' growth and yield. To find rainfall's effects on maize yields, firstly the mean values for each climatic factor except for rainfall were calculated; then the grain yields for each year were predicted using the mean climatic factors and the rainfall condition in the corresponding modeled year with parameters in Tables 1 and 2. The predicted grain yields and their corresponding seasonal rainfall are showed in the Figure 10. It is clearly showed that rainfall amount of higher than $450 \mathrm{~mm}$ will not greatly affect grain yields. When rainfall amount is lower than $450 \mathrm{~mm}$, grain yields are generally decreasing with the rainfall decrease. But it should be noted that, these points for rainfall lower than $450 \mathrm{~mm}$ are much scattered (Figure 10a). This may be due to the rainfall' distribution in the maize growth season.

There are 12 seasons with rainfall amount lower than $450 \mathrm{~mm}$. The rainfall amount for each growth stage were summarized, i.e. seedling stage (May 1-30), elongating stage (from June 1 to July 10), flowering and grain filling stage (from July 11 to August 25), and harvest stage (from August 26 to September 26) for these 12 
seasons. It is found that, grain yields are not significantly $(p>0.05)$ affected by the rainfall amount in the seedling, elongation and harvest stages, but significantly $(p<0.05)$ related to rainfall amount in the flowering and milking stage (Figure 10b). In the seedling stage, maize plants are small; therefore, they need less water. However, in the harvest stage, maize is coming to the end stage and has smaller active leaf area, they also need less water. So in the seedling and harvest stage, crop yields did not greatly relate to rainfall amount. Though maize grows fast and evapotranspiration rate is increasing in the elongation stage, the rich soil water storage from the snow in the winter period may provide enough water for plant growth. Therefore, a slight decrease in rainfall in elongation stage also does not significantly affect grain yields. In the

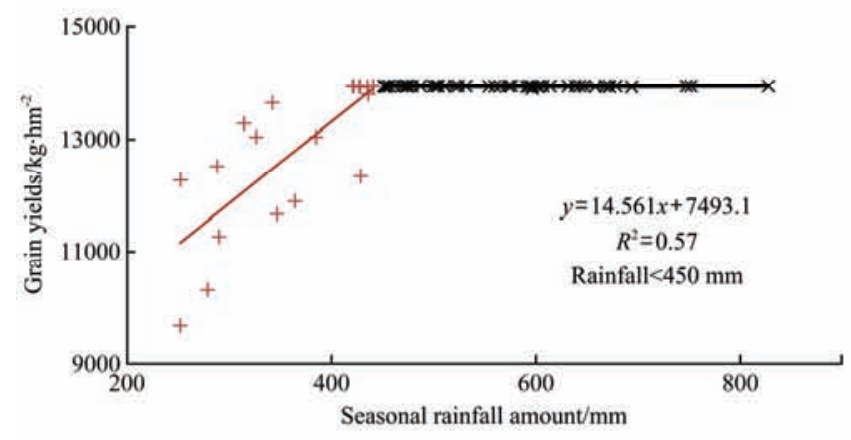

a flowering and grain filling stage, if the depleted soil water in the elongation stage cannot be made up because of less rainfall, soil water will decrease quickly under the higher evapotranspiration condition, and after then, this low soil water condition may limit maize growth and lastly reduce grain yield. Figure 10b shows that a decrease of $100 \mathrm{~mm}$ rainfall in the flowering and grain filling stage will result in a yield reduction of approximately $2000 \mathrm{~kg} / \mathrm{hm}^{2}$. Similarly, Sun et al. ${ }^{[25]}$ found that maize yield is positively related to rainfall amount in both aeolian sandy soil and black soil in the Northeast China. In a conclusion, grain yields may be reduced when seasonal rainfall is less than $450 \mathrm{~mm}$, especially when rainfall is much low in the flowering and grain filling stage.

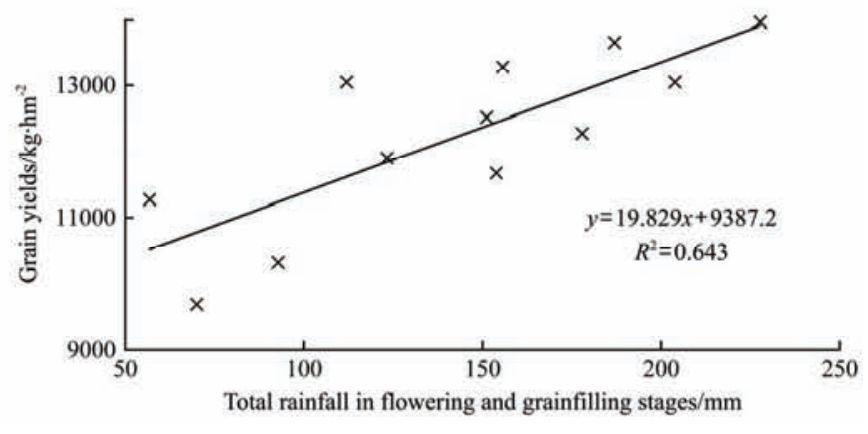

b

Figure 10 Relationships of grain yields with seasonal rainfall amount (a) and rainfall amount in flowering and grain filling stage (b)

\subsection{Case studies on yield reductions in three special years}

In Figure 8, grain yields were much low in 1954, 2000 and 2009 seasons, they were $7177 \mathrm{~kg} / \mathrm{hm}^{2}, 6438 \mathrm{~kg} / \mathrm{hm}^{2}$ and $7296 \mathrm{~kg} / \mathrm{hm}^{2}$, respectively. These yields were much smaller than the yield of $15442 \mathrm{~kg} / \mathrm{hm}^{2}$ in the normal year of 1988 . In the normal year in 1988 , the temperature is suitable for plant growth, and rainfall is distributed uniformly and rainfall amount is enough for plant evapotranspiration. Under the same field management, the great difference in maize yields between these three special years (i.e. 1954, 2000 and 2009) and the normal year of 1988 is mainly due to the climatic variation. The climatic factors in these three special years and the normal year of 1988 are summarized in Table 8.
The plant growth parameters (LAI and dry biomass above ground surface) and grain yields are modeled by RZWQM with parameters in Tables 1 and 2, and results are showed in Figure 11 and Table 8.

To find the key factors affecting grain yield changes in 1954, 1988 and 2000, the grain yields were predicted by replacing one climatic factor with the mean values averaged over years from 1951-2015, and kept other climatic factors in their actual value in the modeled year. When predicted yield greatly differs with the yields without climatic data replacement, it means this replaced climatic variable is one of key factors that influence grain yield. The predicted yields and their change percentages after replacing each climatic factor are showed in Table 9.

Table 8 Seasonal mean/total climatic factors and predicted yields in the special years of 1954, 2000 and 2009 and the normal year of 1988

\begin{tabular}{ccccccc}
\hline Years & $T_{\min } /{ }^{\circ} \mathrm{C}$ & $T_{\max } /{ }^{\circ} \mathrm{C}$ & $T_{\text {mean }} /{ }^{\circ} \mathrm{C}$ & Wind $/ \mathrm{m}^{-1}{ }^{-1}$ & RH $/ \%$ & Precipitation $/ \mathrm{mm}$ \\
\hline 1954 & 13.64 & 23.85 & 18.45 & 3.8 & 74 & 7177 \\
2000 & 16.90 & 27.48 & 22.05 & 2.5 & 64 & 63.5 \\
2009 & 14.43 & 25.91 & 20.18 & 2.2 & 64 & 728.3 \\
1988 & 15.22 & 25.65 & 20.13 & 2.6 & 72 & 251.8 \\
\hline
\end{tabular}
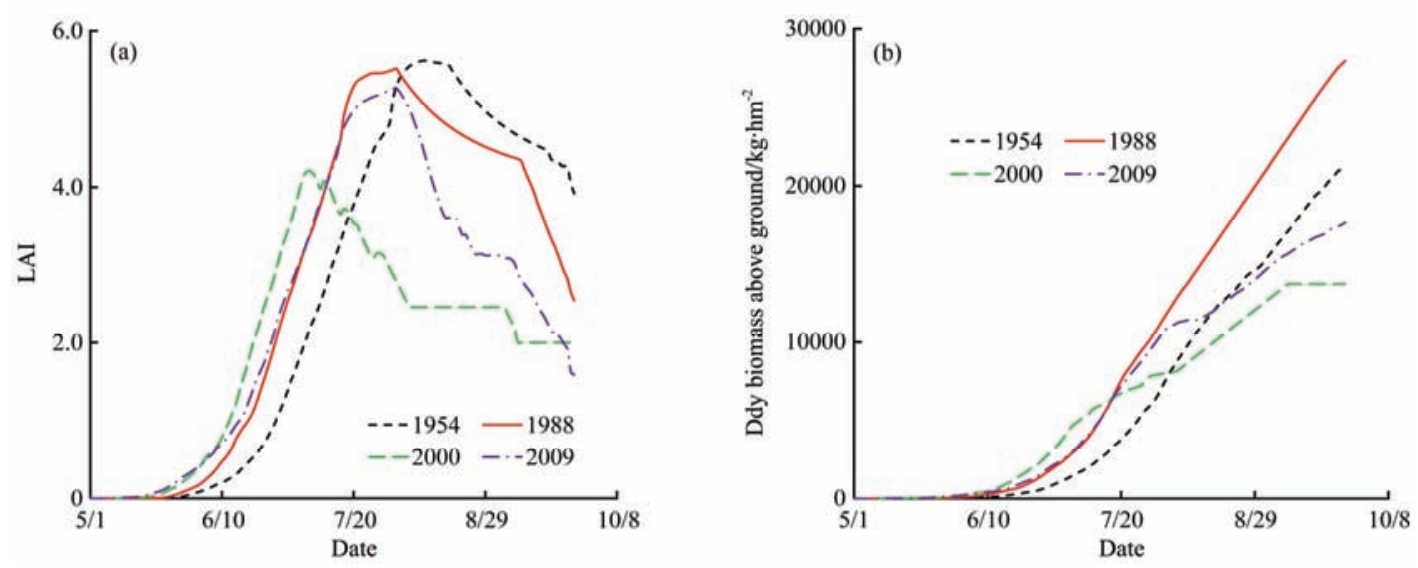

Figure 11 Predicted LAI and dry biomass above ground surface for 1954, 1988, 2000 and 2009 seasons 
Table 9 Effects of each climate factor to grain yields in 1954, 2000 and 2009 seasons

\begin{tabular}{llccccc}
\hline \multirow{2}{*}{ Years } & Items & \multicolumn{5}{c}{$\begin{array}{c}\text { Predicted yields and its change percentage after } \\
\text { replacing a climatic factor }\end{array}$} \\
\cline { 3 - 7 } & & $T_{\min }$ & $T_{\max }$ & Wind & $\mathrm{RH}$ & Precipitation \\
\hline \multirow{2}{*}{1954} & Yield $/ \mathrm{kg} \cdot \mathrm{hm}^{-2}$ & 10335 & 11216 & 7177 & 7177 & 7177 \\
& Change rate $/ \%$ & 44.0 & 56.3 & 0.0 & 0.0 & 0.0 \\
\hline \multirow{2}{*}{2000} & Yield $/ \mathrm{kg} \cdot \mathrm{hm}^{-2}$ & 8749 & 8877 & 6437 & 6437 & 12018 \\
& Change rate $/ \%$ & 35.9 & 37.9 & 0.0 & 0.0 & 86.7 \\
\hline \multirow{2}{*}{2009} & Yield $/ \mathrm{kg} \cdot \mathrm{hm}^{-2}$ & 7011 & 5546 & 7296 & 7296 & 14500 \\
& Change rate $/ \%$ & -3.9 & -24.0 & 0.0 & 0.0 & 98.7
\end{tabular}

Note: Climatic factor's effect was evaluated by the yield difference between under really measured climatic condition and the condition with replacing one climatic factor with their mean values and keeping others as the really measured ones. Positive change rate indicates this real climatic factor reduce grain yield compared to the mean condition.

\subsubsection{4 maize growth season}

In the 1954 season, when $T_{\min }$ and $T_{\max }$ were replaced by their average values over the last 65 years, grain yields increased by $44 \%$ and $56 \%$, respectively (Table 8 ). Considering the positive relationship between grain yields and $T_{\min }$ and $T_{\max }$ (Figure 9), the increase in yield when $T_{\min }$ and $T_{\max }$ were replaced indicates that the average $T_{\min }$ and $T_{\max }$ were much higher than those in the 1954 season, and it is confirmed in the Figure 12. The lower $T_{\min }$ and $T_{\max }$ in the 1954 season greatly limited maize growth and yield production in this energy limited region (Table 8). From May to July, the $T_{\min }$ and $T_{\max }$ in the 1954 season were $2.1^{\circ} \mathrm{C}$ and $2.3^{\circ} \mathrm{C}$ lower than the corresponding averaged values, respectively (Figure 12). These low $T_{\min }$ and $T_{\max }$ delayed the plant growth, especially in the first half growth season. The maximum LAI in the 1954 season was found on August 12, about $10 \mathrm{~d}$ later compared to those in the 1988 season. This growth delay caused dry biomass increasing slowly from May to July, and lastly made yield reduction by about $54 \%$ as compared to the normal year yield in 1988 (Figure 11). The precipitation amount in 1954 was $594 \mathrm{~mm}$ (Table 8). This water was enough for maize growth (Figure 10) and therefore showed slight effects on maize yields (Table 9). Wind speed and relative humidity also slightly affected maize growth and yields.

It can be concluded that, the great reduction in grain yield in the 1954 seasons was mainly because of the low $T_{\min }$ and $T_{\max }$, while other climatic factor did slight effect on grain yield variation. One method to release the low temperature' effect is to cover the soil surface with plastic sheet. It has been confirmed that plastic mulching can increase soil temperature by $1{ }^{\circ} \mathrm{C}-9^{\circ} \mathrm{C}$ in the top soil layer, which not only is benefit to seed germination and plant growth, but also extent growth period, and lastly increase crop yield ${ }^{[44-47]}$. Wang et al. ${ }^{[48]}$ reported that in the North China, compared to non-mulching condition, plastic mulching increased soil temperature by $2{ }^{\circ} \mathrm{C}-2.4^{\circ} \mathrm{C}$ in the first $60 \mathrm{~d}$ after planting, which advanced seed emergence, tasseling and silking, and lastly increased maize yields by $47 \%-159 \%$. Till now, the plastic mulching method has been widely used and studied in the north China for both increasing soil temperature in the beginning growth stage and decreasing soil evaporation ${ }^{[14,46,49]}$. Therefore, it is easy to suggest farmer to use plastic mulching in farmland. Another method is to use some low temperature-resistant maize varieties when the temperature in the following season is predicted to be cool.
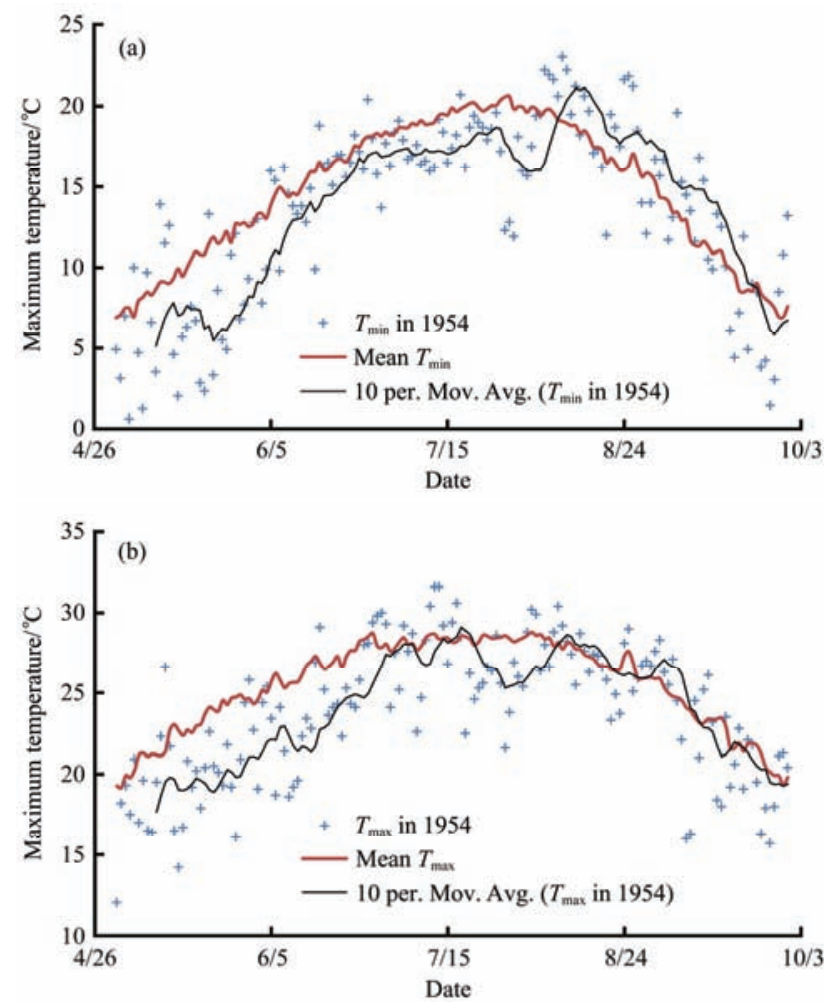

Figure 12 Minimum and maximum temperatures curves in the 1954 season and their mean values averaged over period from 1951 to 2015

\subsubsection{0 maize growth season}

In the 2000 season, the first limit factor for maize production was rainfall amount, which reduced grain yields by $87 \%$ as compared those in the 1988 season (Table 8). The following factors were minimum and maximum temperatures, they both reduced yields by $36 \%$ and $38 \%$, respectively.

The seasonal rainfall amount in the 2000 season was $430 \mathrm{~mm}$, which is about $90 \mathrm{~mm}$ lower than the normal year of 1988 $(520 \mathrm{~mm})$. The significant difference in rain between in the 2000 and 1988 seasons is the seasonal rainfall distributions. In the normal season in 1988, rainfall distributed much uniformly (Figure 13), and matched the maize evapotranspiration process. While in the 2000 season, the total rainfall amount from June 22 to August 6 was $36 \mathrm{~mm}$. In this period, maize is in the elongation and flowering stages, and the crop evapotranspiration in this period may reach $170 \mathrm{~mm}$ under water sufficient condition. The great water deficit of $135 \mathrm{~mm}$ between crop water demand and water supply (i.e. rainfall) significantly limited plant growth and negatively affected LAI and biomass (Figure 11), and lastly accounted for $85 \%$ of grain yields reduction (Table 8 ).

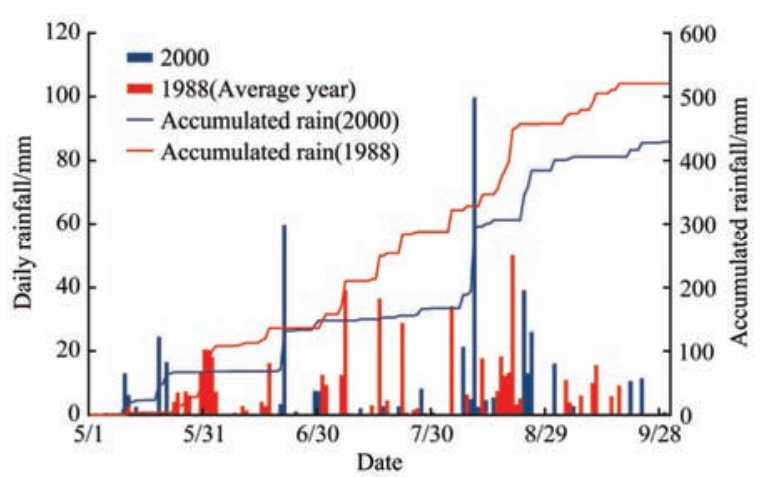

Figure 13 Seasonal distributions of daily rainfall in 2000 and the average year of 1988 
Table 9 also shows that the $T_{\min }$ and $T_{\max }$ are another two key factors to limit grain yields. The mean $T_{\min }$ and $T_{\max }$ in 2000 season were $16.9^{\circ} \mathrm{C}$ and $24.8^{\circ} \mathrm{C}$, respectively, and were corresponding $1.7^{\circ} \mathrm{C}$ and $1.8^{\circ} \mathrm{C}$ higher than their mean values throughout the entire growth period (Figure 14). The great higher temperature enhanced plant growth in the beginning period (Figure 11 ), and also simultaneously resulted in more soil water depletion for crop transpiration. This case quickly posed the unbalance between soil water application and water uptake by crops in the following growth period, and lastly posed water deficit for crops, especially when rainfall is limit. As a result, plant growth factors, including LAI and biomass stopped increasing or even began to decrease (Figure 11) when suffering great water stress and high temperature, and lastly grain yields reduced. Further, the greatest yield response to extra heat are reduced grain number (sterility and abortion of grains) during anthesis to early grain filling; as well as the reduced duration of grain filling ${ }^{[8,9,50]}$.
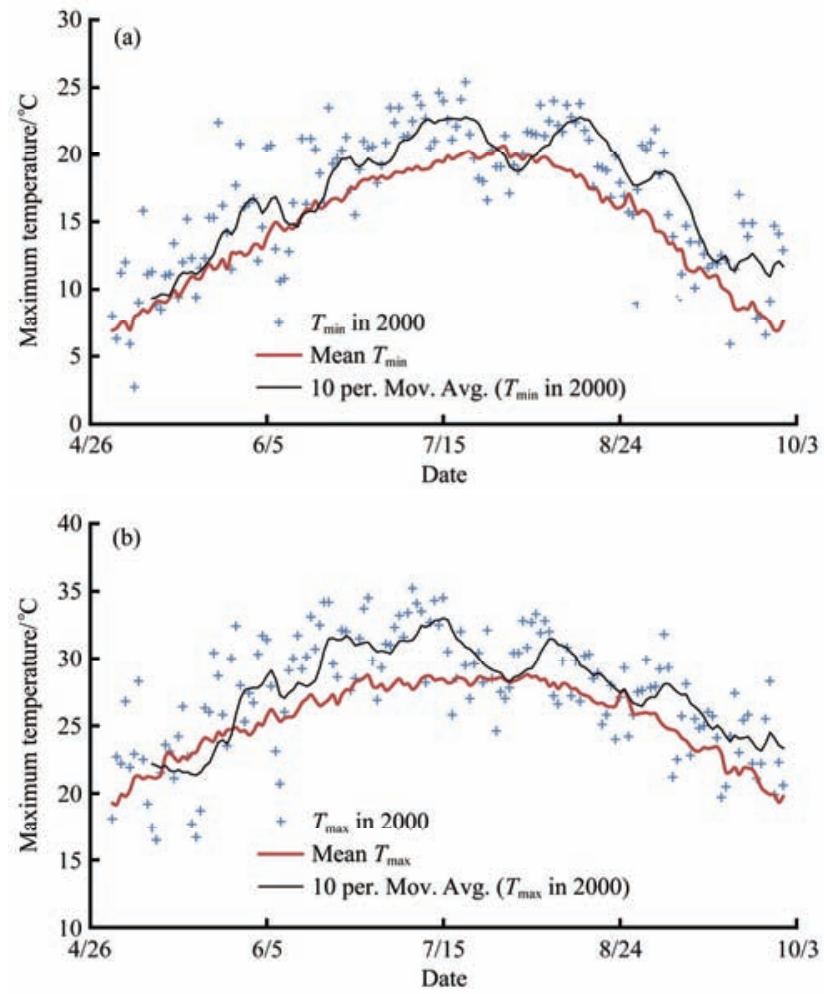

Figure 14 Minimum and maximum temperature curves in the 2000 season and seasonal curves of their mean values averaged over period from 1951 to 2015

Therefore, it is clearly concluded that both the limit rainfall, especially in the elongation and flowering stages $(36 \mathrm{~mm})$, and the extra high temperature during the entire growth period caused the reduction of grain yields in the 2000 season. To release water deficit in the elongation and flowering stages $(36 \mathrm{~mm})$, an irrigation event can be applied to the maize. Also if the climate in the following growth seasons is predicted as a warm season, the farmer may be suggested to use some warm-resistant maize varieties to reduce the risk of much heat's effect on crop yield $^{[11,16,19]}$.

3.4.3 The 2009 maize growth season

In the 2009 season, rainfall is the most dominated factor for grain yields reduction. The total rainfall amount in the 2009 season was $252 \mathrm{~mm}$ and about half of those in the normal year of 1988 season (Table 8). The rainfall deficit resulted in yields reduction by $99 \%$ (Table 9). Figure 15 shows that, there was a great reduction in rainfall throughout the growth season, especially in the August and September. This period is within the flowering and grain filling stages. Water deficit in this period may reduce grain filling period, and then reduce the grain mass per unit, which lastly cause yield reduction. Statistical result in Figure 10b shows a linear relationship between grain yield and water deficit in the flowering and grain filling stage. Therefore, water deficit in the August and September in the 2009 season may greatly reduce maize yield. Figure 11 shows that there was no big difference in LAI and biomass before August. However, after that point, LAI decreased quickly, and caused biomass increasing slightly, mainly because of the rainfall shortage in this period. In a conclusion, rainfall deficit, especially in the period from August to September, was the main factor for grain yields reduction in the 2009 season. Therefore, it is important to irrigate maize during this period to release the water stress.

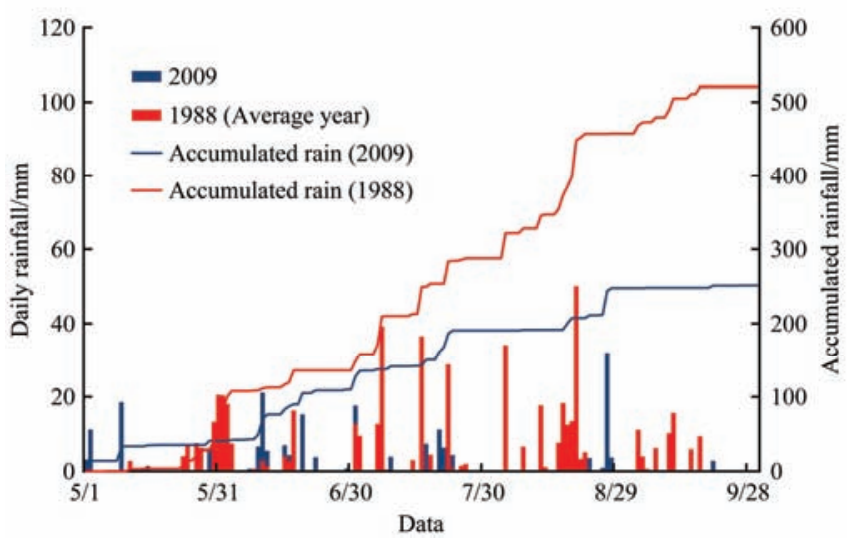

Figure 15 Seasonal distributions of daily rainfall in 2009 and the average year of 1988

\section{Conclusions}

(1) In this study, the RZWQM model was calibrated and validated using the field data measured in 2014 and 2015 maize seasons. The MRE ranged from $-10 \%$ to $10 \%$, and $r^{2}$ ranged from 0.5 to 0.8 during the model calibration and validation processes for predicting soil water, leaf index, biomass and grain yields, indicating RZWQM can be successfully applied in the Siping as well as the Northeast China.

(2) The predicted grain yields of maize ranged from 6438 to $15442 \mathrm{~kg} / \mathrm{hm}^{2}$ with a mean value of $12086 \mathrm{~kg} / \mathrm{hm}^{2}$ in the study region. Grain yields generally positively related to seasonal minimum, maximum and mean air temperatures, and also to the rainfall amount in the flowering and grain filling stages when the seasonal rainfall is less than $450 \mathrm{~mm}$.

(3) In the 1954 season, the lower $T_{\min }$ and $T_{\max }$ by $2.1^{\circ} \mathrm{C}$ and $2.3^{\circ} \mathrm{C}$ than the averaged values resulted in maize yield reduction by $41 \%$. In the 2009 season, small rainfall amount of $252 \mathrm{~mm}$, especially no rainfall in the August, was the main reason for yield reduction of $40 \%$. And in the 2000 season, a less rainfall amount of $36 \mathrm{~mm}$ in the elongation and flowering stages is the main reason for yield reduction, the second reason was the higher $T_{\min }$ and $T_{\max }$ throughout the growth season.

(4) Supplementary irrigation in the flowering and grain filling stages is important for maintaining normal yields when rainfall is very little in this stage. Maize species should be chose depending on the longtime weather forecast. 


\section{Acknowledgements}

This research was funded by The National Key Research and Development Program of China (2017YFD0201500) and the 111 Project (B18006). All authors really appreciated the staffs in the Lishu Experimental Station of China Agricultural University for their supports in our experimental period.

\section{[References]}

[1] IPCC. Climate change 2013: The physical science basis. Contribution of working group i to the fifth assessment report of the intergovernmental panel on climate change. Cambridge University Press, Cambridge, United Kingdom and New York, NY, USA, 2013; 1535 pp.

[2] Porter J R, Xie L, Challinor A J, Cochrane K, Howden S M, Iqbal M M, et al. Food security and food production systems. In: Field $\mathrm{C} \mathrm{B}$, Barros $\mathrm{V}$ R, Dokken D J, Mach K J, Mastrandrea M D, Bilir T E, et al. (Editors), Climate change 2014: Impacts, adaptation, and vulnerability. Part A: Global and sectoral aspects. contribution of working group ii to the fifth assessment report of the intergovernmental panel on climate change. Cambridge University Press, Cambridge, United Kingdom and New York, NY, USA, 2014; pp. 485-533.

[3] Chen Y, Wu Z, Okamoto K, Han X, Ma G, Chien H et al. The impacts of climate change on crops in China: A Ricardian analysis. Glob. Planet. Change, 2013; 104: 61-74.

[4] Ding T, Qian W, Yan Z. Changes in hot days and heat waves in China during 1961-2007. Int J Climatol, 2010; 30(10): 1452-1462.

[5] Middleton N J, Sternberg T. Climate hazards in drylands: A review. Earth-Sci Rev, 2013; 126: 48-57.

[6] Shannon H D, Motha R P. Managing weather and climate risks to agriculture in North America, Central America and the Caribbean. Weather Clim Extremes, 2015; 10, Part A: 50-56.

[7] Johansson R, Luebehusen E, Morris B, Shannon H, Meyer S. Monitoring the impacts of weather and climate extremes on global agricultural production. Weather Clim Extremes, 2015; 10, Part A: 65-71.

[8] Barlow K M, Christy B P, O’Leary G J, Riffkin P A, Nuttall J G. Simulating the impact of extreme heat and frost events on wheat crop production: A review. Field Crop Res, 2015; 171: 109-119.

[9] Hatfield J L, Prueger J H. Temperature extremes: Effect on plant growth and development. Weather Clim Extremes, 2015; 10, Part A: 4-10.

[10] NBSC. China statistical yearbook 2015. China Statistics Press, 2015, Beijing. (in Chinese)

[11] Byjesh K, Kumar S N, Aggarwal P K. Simulating impacts, potential adaptation and vulnerability of maize to climate change in India. Mitig Adapt Strateg Glob Chang, 2010; 15(5): 413-431.

[12] Abate T, Shiferaw B, Menkir A, Wegary D, Kebede Y, Tesfaye K, et al. Factors that transformed maize productivity in Ethiopia. Food Secur, 2015; 7(5): 965-981.

[13] Ahmadi S H, Mosallaeepour E, Kamgar-Haghighi A A, Sepaskhah A R. Modeling maize yield and soil water content with AquaCrop under full and deficit irrigation managements. Water Resour Manage, 2015; 29(8): 2837-2853.

[14] Liu Z, Yang X, Lin X, Hubbard K G, Lv S, Wang J. Maize yield gaps caused by non-controllable, agronomic, and socioeconomic factors in a changing climate of Northeast China. Sci Total Environ, 2016; 541: 756-764.

[15] Yang L, Yan B X, Cui T, Yu Y M, He X T, Liu Q, et al. Global overview of research progress and development of precision maize planters. Int $\mathrm{J}$ Agric Biol Eng, 2016; 9(1): 9-26.

[16] Chen C, Lei C, Deng A, Qian C, Hoogmoed W, Zhang W. Will higher minimum temperatures increase corn production in Northeast China? An analysis of historical data over 1965-2008. Agric Forest Meteorol, 2011; 151(12): 1580-1588.

[17] Chen C, Qian C, Deng A, Zhang W. Progressive and active adaptations of cropping system to climate change in Northeast China. Eur J Agron, 2012; 38: 94-103.

[18] Zhao C Y, Ying W, Xiao Y Z, Yan C, Yu-Lian L, Da-Ming S, et al. Changes in climatic factors and extreme climate events in Northeast China during 1961-2010. Adv Clim Chang Res, 2013; 4(2): 92-102.

[19] Xu Y, Guo J, Zhao J, Mu J. Scenario analysis on the adaptation of different maize varieties to future climate change in Northeast China. J Meteorol Res, 2014; 28(3): 469-480.

[20] Ma L, Hoogenboom G, Ahuja L R, Ascough Ii J C, Saseendran S A.
Evaluation of the RZWQM-CERES-Maize hybrid model for maize production. Agric Syst, 2006; 87(3): 274-295.

[21] Ma L, Malone R W, Heilman P, Jaynes D B, Ahuja L R, Saseendran S A, et al. RZWQM simulated effects of crop rotation, tillage, and controlled drainage on crop yield and nitrate-N loss in drain flow. Geoderma, 2007; 140(3): 260-271.

[22] Ma L, Ahuja L R, Islam A, Trout T J, Saseendran S A, Malone R W. Modeling yield and biomass responses of maize cultivars to climate change under full and deficit irrigation. Agric Water Manage, 2017; 180: 88-98.

[23] Islam A, Ahuja L R, Garcia L A, Ma L, Saseendran A S, Trout T J. Modeling the impacts of climate change on irrigated corn production in the Central Great Plains. Agric Water Manage, 2012; 110: 94-108.

[24] Wang Z, Qi Z, Xue L, Bukovsky M, Helmers M J. Modeling the impacts of climate change on nitrogen losses and crop yield in a subsurface drained field. Clim Change, 2015; 129(1): 323-335.

[25] Sun Z, Li Z, Lu X, Bu Q, Ma X, Wang Y. Modeling soil type effects to improve rainfed corn yields in Northeast China. Agronomy Journal, 2016; 108(2): 498-508.

[26] Ma L, Ahuja L R, Ascough Ii J C, Shaffer M J, Rojas K W, Malone R W, et al. Integrating system modeling with field research in agriculture: applications of the root zone water quality model (RZWQM), Advances in Agronomy. Academic Press, 2001; pp. 233-292.

[27] Ma L, Malone R W, Heilman P, Karlen D L, Kanwar R S, Cambardella C A, et al. RZWQM simulation of long-term crop production, water and nitrogen balances in Northeast Iowa. Geoderma, 2007; 140(3): 247-259.

[28] Saseendran S A, Trout T J, Ahuja L R, Ma L, McMaster G S, Nielsen D C, et al. Quantifying crop water stress factors from soil water measurements in a limited irrigation experiment. 2015; 137: 191-205.

[29] Qi Z, Ma L, Walter C B, Thomas J T, Lajpat R A, Gerald N F, et al. Simulating maize production, water and surface energy balance, canopy temperature, and water stress under full and deficit irrigation. Trans ASABE, 2016; 59(2): 623-633.

[30] Yu Q, Saseendran S A, Ma L, Flerchinger G N, Green T R, Ahuja L R. Modeling a wheat-maize double cropping system in China using two plant growth modules in RZWQM. Agric Syst, 2006; 89(2-3): 457-477.

[31] Cameira M R, Fernando R M, Ahuja L R, Ma L. Using RZWQM to simulate the fate of nitrogen in field soil-crop environment in the Mediterranean region. Agric Water Manage, 2007; 90(1-2): 121-136.

[32] Ma L, Trout T J, Ahuja L R, Bausch W C, Saseendran S A, Malone R W, et al. Calibrating RZWQM2 model for maize responses to deficit irrigation. Agric Water Manage, 2012; 103: 140-149.

[33] Loague K, Green R E. Statistical and graphical methods for evaluating solute transport models: Overview and application. J Contam Hydrol, 1991; 7(1): 51-73.

[34] Liu H J, Zhang R H, Zhang L W, Wang X M, Li Y, Huang G H. Stemflow of water on maize and its influencing factors. Agric Water Manage, 2015; 158: 35-41.

[35] Allen R G, Pereira L S, Raes D,d Smith M. Crop evapotranspiration:guidelines for computing crop water requirements. Irrigation and DrainagePaper 56. Food and Agriculture Organization of the United nations, Rome, 1998.

[36] Liu Z, Yang X, Hubbard K G, Lin X. Maize potential yields and yield gaps in the changing climate of northeast China. Glob Change Biol, 2012; 18(11): 3441-3454.

[37] Xu J, Li C, Liu H, Zhou P, Tao Z, Wang P, et al. The effects of plastic film mulching on maize growth and water use in dry and rainy years in northeast china. PLoS ONE, 2015; 10(5): e0125781.

[38] Guo J, Zhao J, Wu D, Mu J, Xu Y. Attribution of maize yield increase in China to climate change and technological advancement between 1980 and 2010. J Meteorol Res, 2014; 28(6): 1168-1181.

[39] Liu Z, Yang X, Chen F, Wang E. The effects of past climate change on the northern limits of maize planting in Northeast China. Clim Change, 2013; 117(4): 891-902.

[40] Wang X, Peng L, Zhang X, Yin G, Zhao C, Piao S. Divergence of climate impacts on maize yield in Northeast China. Agric Ecosyst Environ, 2014; 196: 51-58.

[41] Zhao J, Guo J, Mu J. Exploring the relationships between climatic variables and climate-induced yield of spring maize in Northeast China. Agric Ecosyst Environ, 2015; 207: 79-90.

[42] Dong W, Zhang L, Duan Y, Sun L, Zhao P, van der Werf W, et al. Ridge and furrow systems with film cover increase maize yields and mitigate climate risks of cold and drought stress in continental climates. Field Crop Res, 2017; 207: 71-78. 
[43] Sui J, Wang J, Gong S, Xu D, Zhang Y, Qin Q. Assessment of maize yield-increasing potential and optimum $\mathrm{N}$ level under mulched drip irrigation in the Northeast of China. Field Crop Res, 2018; 215: 132-139.

[44] Ramakrishna A, Tam H M, Wani S P, Long T D. Effect of mulch on soil temperature, moisture, weed infestation and yield of groundnut in northern Vietnam. Field Crops Res., 2006; 95(2-3): 115-125.

[45] Wang F X, Feng S Y, Hou X Y, Kang S Z, Han J J. Potato growth with and without plastic mulch in two typical regions of Northern China. Field Crop Res, 2009; 110(2): 123-129.

[46] Dang J, Liang W, Wang G, Shi P, Wu D. A preliminary study of the effects of plastic film-mulched raised beds on soil temperature and crop performance of early-sown short-season spring maize (Zea mays L.) in the North China Plain. Crop J, 2016; 4(4): 331-337.
[47] Steinmetz Z, Wollmann C, Schaefer M, Buchmann C, David J, Tröger J, et al. Plastic mulching in agriculture. Trading short-term agronomic benefits for long-term soil degradation? Sci Total Environ, 2016; 550: 690-705.

[48] Wang L, Li X G, Guan Z H, Jia B, Turner N C, Li F M. The effects of plastic-film mulch on the grain yield and root biomass of maize vary with cultivar in a cold semiarid environment. Field Crop Res, 2018; 216 : 89-99.

[49] Hou X Y, Wang F X, Han J J, Kang S Z, Feng S Y. Duration of plastic mulch for potato growth under drip irrigation in an arid region of Northwest China. Agric Forest Meteorol, 2010; 150(1): 115-121.

[50] Liu H J, Kang Y. Regulating field microclimate using sprinkler misting under hot-dry windy conditions. Biosyst Eng, 2006; 95(3): 349-358. 